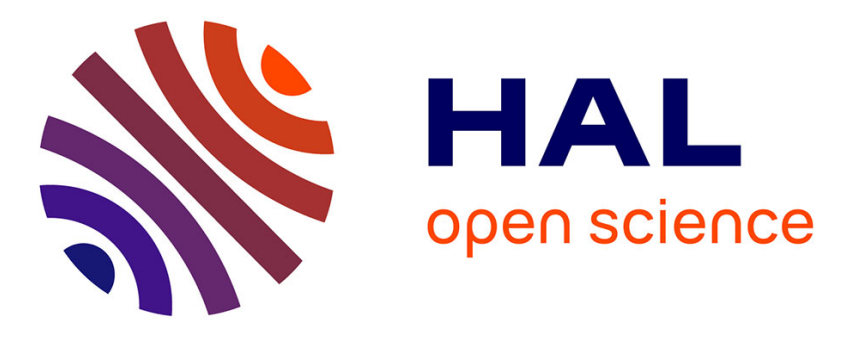

\title{
Digital Technology for Preserving Cultural Heritage in Tonga
}

\author{
'anau Mesui, Antonio Diaz Andrade, Lena Waizenegger
}

\section{To cite this version:}

'anau Mesui, Antonio Diaz Andrade, Lena Waizenegger. Digital Technology for Preserving Cultural Heritage in Tonga. 15th International Conference on Social Implications of Computers in Developing Countries (ICT4D), May 2019, Dar es Salaam, Tanzania. pp.215-226, 10.1007/978-3-030-19115-3_18 . hal-02281296

\section{HAL Id: hal-02281296 https://hal.inria.fr/hal-02281296}

Submitted on 9 Sep 2019

HAL is a multi-disciplinary open access archive for the deposit and dissemination of scientific research documents, whether they are published or not. The documents may come from teaching and research institutions in France or abroad, or from public or private research centers.
L'archive ouverte pluridisciplinaire HAL, est destinée au dépôt et à la diffusion de documents scientifiques de niveau recherche, publiés ou non, émanant des établissements d'enseignement et de recherche français ou étrangers, des laboratoires publics ou privés. 


\title{
Digital Technology for preserving cultural heritage in Tonga
}

\author{
'Anau Mesui ${ }^{1}$ and Antonio Diaz Andrade ${ }^{2}$ and Lena Waizenegger ${ }^{3}$ \\ 1,2,3 Auckland University of Technology, Auckland, New Zealand
}

\begin{abstract}
Cultural heritage embodies and carries the stories and values of our ancestors that define our understanding of who we are today. A society's heritage serves an important purpose for educating people about their own culture and aiding in understanding their traditional values. In Tonga, where this research has been conducted, the historical knowledge and cultural values have been usually transferred orally from generation to generation. However, due to the pressures of globalisation, westernisation and migration, cultural heritage is under threat. These threats can potentially impede the transferring of societies' idiosyncratic identity to future generations and erode cultural life. ICT as an option to preserve cultural heritage offers opportunities to not only capture and immortalise tangible and intangible cultural artefacts but also enables the accessibility of those artefacts to a wider audience through the internet. It is against this background that we explore how digital technologies are utilised in the process of preserving cultural heritage.
\end{abstract}

Keywords: ICT4D, Social Embeddedness, Preserving Cultural Heritage

\section{Introduction}

Oral traditions have maintained the sea navigation skills and astronomy that asserted Tonga's maritime chiefdom for over 2000 year [1] . However, this ancient navigation knowledge is now at risk of being eroded due to modernisation, globalisation and especially due to various technological developments such as Geographic Information Systems (GIS). This is just an example that illustrates that cultural heritage in Tonga is threatened. Other Pacific nations such as Fiji are utilising ICT to create a virtual museum that supports the safeguarding of cultural artefacts making it accessible to the community [2]. Fiji's virtual museum has audio narrations, a zoom function, and descriptions on artefacts, such as Lapita pottery and even traditional Tongan weapons [2]. As such, information and communication technology (ICT) can play a role in maintaining cultural knowledge. In order to improve our understanding of the potential of ICT for the preservation of cultural heritage in Tonga we aim to answer the research question: How is ICT utilised in the process of preserving cultural heritage in Tongan?

In order to answer this question, we adopt an interpretive case study [3] approach which involved talanoa -a Pacific research method that focuses on relationship building and complying with the cultural protocols [4]. The interviews in the form of talanoa were conducted with Tongan individuals who consider the use of ICT to pre- 
serve cultural heritage in their workplace. By doing so, we cater to the Tongan cooperative attitude and collaborative assumptions as opposed to relying on frameworks developed in other contexts. We argue that by investigating locally developed solutions for safeguarding Tongan cultural heritage by a Tongan researcher, we enhance the understanding of indigenous perspectives in ICT4D initiatives.

\section{Background}

Tonga has a rich history that tells stories of the thriving Tongan maritime chiefdom that was technologically advanced in its time. Additional cultural richness includes the Tongan traditional arts: nimamea'a (fine arts), tufunga (material arts) and faiva (performance arts). For example, the lakalaka is part of the faiva category and is a genre of music and traditional dance in which Tongans chant about the natural features, places and history of the more than 170 islands that make what is now known as the Kingdom of Tonga. Furthermore, traditional sports stories include the sia heu lupe, a circular, flat topped mounds related to an ancient sport - pigeon snaring reserved for chiefs [1] - that is linked to possible star constellations associated with ancient forms of Tongan navigation. The physical remains of culture in the form of historical sites conserves Tonga's rich cultural heritage which is essential to providing an understanding of who Tongans are, where they have come from - their past feats as traditional warriors and great navigators - and therefore, what they are capable of achieving - their future.

The use of ICT for preserving cultural heritage in Tonga is minimally adopted within organisations, whilst other Moana (Pacific) nations, such as Fiji [2], [5] have recognised the potential of ICT not only to conserve their cultural heritage but also to disseminate it. Different views exist in Tonga on how, what and why cultural heritage should be preserved, and the role digital technology can play in this process. For instance, the idea of a museum to preserve cultural artefacts is questioned in Tonga, whose citizens are proud of their living and breathing culture. The clash of traditional and modern views of cultural heritage preservation, is a process of tension, transformation and transitioning currently taking place in Tonga, which we want to investigate by adopting a social embeddedness approach [6]. This allows us to gain an indepth understanding of the role ICT plays in preserving cultural heritage in relation to local cultural beliefs, values and norms from a local Tongan perspective. To explore the utilisation of ICT within the local context, it is essential to identify how local Tongans perceive ICT and the process of preservation. Furthermore, locating what cultural, economic and or political factors in Tonga may impact or inform these local perceptions can provide understanding into how ICT can be used in the process of preserving cultural heritage [6]. 


\section{$3 \quad$ Literature Review}

\subsection{Cultural Heritage}

The interpretation of cultural heritage has evolved significantly over recent decades. Abd Manaf and Ismail [7] define heritage as "our legacy from the past, what we live with today and what we pass on to future generations". Cultural heritage embodies a former way of life and its transmission to the next generation is crucial to the longevity of the culture. Belhi et al. [8] argue that cultural heritage is the only vehicle that can trace the lifecycle of a society and promote the use of digital technologies for passing on cultural knowledge. Culture constitutes sets of core values, beliefs and understandings [7] and their embodiments are manifested in artefacts. Cultural heritage is not limited to just tangible artefacts such as archaeological sites and monuments, but also involves intangible artefacts, such as religious ceremonies, language, practices and oral history [9].

\subsection{The Social Embeddedness Discourse in ICT4D Research}

Heeks [10] ,defines ICT4D as "the application of any entity that processes or communicates digital data in order to deliver some part of the intentional development agenda in a developing country". Heeks definition combines ICT as an entity that communicates or processes digital data, for example - smart phones, tablets, the Internet, computers etc.- and development as a means of focusing on a specific geographic and agenda development, "particularly progressive changes in a developing country". ICT4D studies suggest that ICT can aid the refining of socio-economic conditions in developing countries [11]. The assumption is that ICT4D entails the use of ICT innovations to help individuals or communities develop their potential. However, Walsham [12] suggests that within ICT4D, researchers should perceive themselves as cocontributors along with local actors rather than experts bringing top-down solutions. Furthermore, Walsham [12] highlights that views about development would differ in different local contexts. This aligns with one of Avgerou's [6] three identified discourses occurring in ICT with regard to IS innovation: social embeddedness. The other two discourses are transformative information systems in developing countries (ISDC) and transfer and diffusion discourse [6]. The social embeddedness and transformative in ISDC discourses take into consideration the role of culture in ICT innovation [6]. In the context of this study we define ICT innovation as a process that involves the "development and implementation of ICT systems and concomitant organisational change" [6]. Therefore, applying a social embeddedness lens we looked at what cultural factors in Tonga contribute to how ICT is leveraged in order to preserve cultural heritage in Tonga. As such, the study of ICT innovations always requires understanding of the social context [6].

The social embeddedness discourse guides our study of the utilisation of digital technologies for preserving cultural heritage since it conceptualises ICT innovation as a local process that is comprised of organisational change and technology construction [6]. By applying a social embedded approach, we consider local Tongan per- 
spectives in a collaborative and co-creative partnership to explore and identify solutions for using ICT as an option to safeguard heritage. Local Tongans will better relate to and accept the solutions that fit to their local context and were developed with their contribution. We pay special attention to locally constructed meanings in the presence of digital technologies for preserving cultural heritage in Tonga. For instance, the online material about Tongan kupesi (patterns for printing onto cloth) [13] constitute examples of digital technology utilised to preserve cultural heritage. Although the technologies used may not be sophisticated, the local implementation experience constitutes an ICT innovation. As such, a social embeddedness approach places emphasis on investigating local meanings and exploring locally suitable techno-organisational change [6].

\section{$4 \quad$ Research Method}

We adopted a constructivist perspective [14] and used an interpretive case study approach [3] to collect and analyse data. The case study approach is suitable to gain an in-depth understanding and knowledge of how ICT is utilised in the process of preserving cultural heritage in Tonga, and what the implications are for those involved [3]. This approach is adequate for the highly stratified and hierarchical society of Tonga, where cultural information has been traditionally perceived as something to be guarded rather than to be shared openly [15]. Considering the scarcity of literature about the use of digital technology for preserving cultural heritage in Tonga, we took an explorative perspective and were open to the patterns that were emerging from the data as part of our thematic analysis [14].

\subsection{Data collection}

In order to collect data, we used semi-structured interviews in the form of a talanoa. The talanoa were conducted in Tonga in September 2018 by the first author, who is a Tongan citizen. She was born in Tonga and raised in New Zealand in a conservative Tongan family. Her upbringing provides insider knowledge on the Tongan culture.

Pacific researchers have employed talanoa as a methodology [4] and a method, however, for this study we employ talanoa as a method that adheres to Tongan norms of communication. Talanoa encompass the Tongan worldview of communicating that involves debating, gossiping, reflecting, story-telling, joking, and sharing family connections [4]. The vigorous interactive form of conversating incite deep discussions and relationship. Kepa \& Manu'atu [16] refers to the verb talanoa as a way of conversating, relating to experiences of every-day life and telling stories. Vaioleti [4] affirms that talanoa permits for more meaningful information to become apparent to the Pacific researcher. Mahina [17] advises that the word talanoa is commonly "used to mean a story and, occasionally, an account, an explanation or a description".

Furthermore, due to her cultural background the first author was able to engage in the talanoa form which takes cultural protocols into consideration. For example, by complying with the appropriate dress code such as wearing a kiekie (traditional waist 
garment for women) in particular situations, the first author signaled her own Tongan roots and identified herself as an insider and part of the society. It was an important decision to use the talanoa form in order to carry out communication in a manner that is ethical and familiar to the Tongan mode of conversating and its values.

The first author conducted face-to-face interviews, following the tenets of talanoa, with eight participants and informal interviews in talanoa form with four participants, for an average of 30 minutes to one hour and a half. The eight participants were selected from five organisations or initiatives in Tonga. The selection criteria were based on the level of expertise and knowledge on digital technology and their involvement in preserving cultural heritage. In a hierarchically structured society, interviewing a range of participants increases the probability of attaining honest, rich data reflecting different perspectives. A breakdown of all participants is displayed in Table 1. Please note that all participants and organisations have been assigned pseudonyms to ensure confidentiality.

Table 1. Participant demographics

\begin{tabular}{|c|c|c|c|c|c|}
\hline Group & Participant & Position & Age Group & Gender & Education \\
\hline $\begin{array}{l}\text { Heritage } \\
\text { Support } \\
\text { Group }\end{array}$ & Mele & Leadership & $50 y r s+$ & Female & $\begin{array}{l}\text { Tertiary } \\
\text { Level }\end{array}$ \\
\hline $\begin{array}{l}\text { Advocate } \\
\text { Group }\end{array}$ & Lupe & Leadership & $50 y r s+$ & Female & $\begin{array}{l}\text { Tertiary } \\
\text { Level }\end{array}$ \\
\hline $\begin{array}{l}\text { Government } \\
\text { Agent }\end{array}$ & Sione & Leadership & 35yrs-50yrs & Female & $\begin{array}{l}\text { Tertiary } \\
\text { Level }\end{array}$ \\
\hline $\begin{array}{l}\text { Royal Her- } \\
\text { itage Agent }\end{array}$ & Tangi & $\begin{array}{l}\text { Ranked } \\
\text { Chief }\end{array}$ & 35yrs-50yrs & Male & Unknown \\
\hline $\begin{array}{l}\text { Royal Her- } \\
\text { itage Group }\end{array}$ & 'Uasimoa & $\begin{array}{ll}\begin{array}{l}\text { Office } \\
\text { ployee }\end{array} & \end{array}$ & $18 y r s-34 y r s$ & Female & Unknown \\
\hline $\begin{array}{l}\text { Royal Her- } \\
\text { itage Agent }\end{array}$ & 'Ohai & $\begin{array}{ll}\begin{array}{l}\text { Office } \\
\text { ployee }\end{array} & \\
\end{array}$ & 18yrs-34yrs & Female & Unknown \\
\hline $\begin{array}{l}\text { Government } \\
\text { Agent }\end{array}$ & Fusi & $\begin{array}{l}\text { Office Em- } \\
\text { ployee }\end{array}$ & 35yrs-50yrs & Female & $\begin{array}{l}\text { Tertiary } \\
\text { Level }\end{array}$ \\
\hline $\begin{array}{l}\text { Government } \\
\text { Agent }\end{array}$ & Leka & $\begin{array}{l}\text { Office Em- } \\
\text { ployee }\end{array}$ & 18yrs-34yrs & Female & $\begin{array}{l}\text { Tertiary } \\
\text { Level }\end{array}$ \\
\hline $\begin{array}{l}\text { Community- } \\
\text { based Inter- } \\
\text { est Group }\end{array}$ & Lisiua & $\begin{array}{l}\text { Initiator/Di- } \\
\text { rector }\end{array}$ & $35 y r s-50 y r s$ & Female & Unknown \\
\hline Others & Kameli & Anonymous & 51yrs-65yrs & Female & $\begin{array}{l}\text { High School } \\
\text { Level }\end{array}$ \\
\hline Others & Kapeta & $\begin{array}{ll}\begin{array}{l}\text { Office } \\
\text { ployee }\end{array} & \end{array}$ & 35yrs-50yrs & Female & $\begin{array}{l}\text { High School } \\
\text { Level }\end{array}$ \\
\hline Others & Kepu & $\begin{array}{l}\text { Blue Collar } \\
\text { Entrepre- } \\
\text { neur }\end{array}$ & $50+$ & Male & $\begin{array}{l}\text { High School } \\
\text { Level }\end{array}$ \\
\hline
\end{tabular}

Talanoa were recorded with the voice recorder of a smart phone. The smart phone was selected dues to its unobtrusive, subtle and less threatening size, minimising distractions during a talanoa. Additionally, as approved by the participant, the researcher 
took notes during the talanoa to capture key points, Tongan concepts, and emotions that prevailed throughout the session.

\subsection{Data analysis}

The transcribing of the audio tapes took place in New Zealand at the end of the fieldwork by the researcher and two paid transcribers. Transcripts that were not transcribed by the researcher were checked against the original recording, and notes taken in an attempt to read the data in an active manner [14].

A thematic analysis was undertaken to "identify, analyse, and report patterns (themes) within data” [14].

Applying an inductive approach [14], the coded key words, key points, experiences, ideas, and emotion(s) in order to generate an initial list of codes. The ideas were grouped in a table according to meaningful connections. Meaningful connections were constantly reviewed to organise the data into further meaningful groups [14]. For example, references by participants to a lack of funding, lack of policy and a lack of direction were collated under one group, lack of support. The systematic and consistent approach to identifying codes was applied across each data item.

The next phase involved searching for themes across the different codes. The researcher focused on a thematic analysis on the semantic level to generate themes [14]. On the semantic level, themes are found in the explicit meaning of the data as spoken or written by the participants [14].

The researcher utilised visual representations, in the form of posted notes and coloured markers, to sort the different codes into themes [14]. Each code was organised and rearranged to form connections and relationships. Some initial themes became main themes whilst others, sub-themes. For instance, lack of policy and direction initially grouped under lack of support along-side lack of leadership, became a sub-group of - lack of leadership. Important to note is that the analysis process was a recursive one as opposed to a linear [14].

The last phase of the thematic analysis process was refining, defining and naming the themes [14]. This led to the following preliminary findings which will be outlined in the next section.

\section{$5 \quad$ Preliminary Findings}

Three themes emerged from the data analysis: Awareness of the potential of ICT to preserve cultural heritage, existing challenges that affect the preservation of cultural heritage in Tonga and bottom-up initiatives for preservation of cultural heritage in Tonga. We found that despite the awareness of the potential of ICT to preserve cultural heritage, Tongans face various challenges that hinder their use of technology to safeguard their cultural roots. However, we also found that Tongans try to mitigate these challenges through bottom-up initiatives . 


\subsection{Awareness of the potential of ICT to preserve cultural heritage}

\section{Awareness of the importance of cultural heritage}

Amongst participants there is a strong sentiment that cultural heritage is important and all recognised its preservation as valuable and empowering to the Tongan society.

Lupe remarks, "I think...the most important thing I ever did was being included in the Tu'i Pelehake's ah political and reform committee. Because, I had then the opportunity to go and meet people in their own communities. And listen to them talk about, their passions, their desires, their visions for their future. And that was for me a very enriching experience. Which I don't think I will ever have again, but I was very grateful that I had that opportunity. Because it um, demonstrated and showed me the richness of our culture, and the richness of the Tongan language. When people use it properly. People who know the language and know the history and know the oral history. It was such an eye-opener for me to sit there and listen to these people, sharing their stories and their wisdom over the years. And ah the, the language they used and the example that they drew from it was just, so, empowering."

Fusi who specialises in geographical information system advised that technology can be utilised to identify, capture and create awareness of the importance of historical sites in Tonga. The digitisation allows the preservation and dissemination of knowledge about these tangible sites and its stories. In her work she mainly relies on satellite data, an internal open source software, a database and a scanner to identify and capture the historical sites.

As outlined above ICT is recognised and used as an option that enables, prolongs and supports the continuance, storage and disseminating of cultural heritage in Tonga. However, the participants also emphasised the importance of traditional methods of preservation such as traditional arts - for instance faiva and tapa making- memory and book form, kava circles and family storytelling which was highlighted by Mele, Lupe, Tangi, Kameli and Kepu, indicating that digital technology and traditional methods are not mutually exclusive. Therefore, from the perspectives of local Tongans ICT and traditional methods both play an essential role in safeguarding their heritage.

\subsection{Existing challenges that affect the preservation of cultural heritage in Tonga}

Despite the awareness of ICT and its perceived value and benefits as an option to safeguard heritage, participants face the challenge of a lack of governmental ICT legislation to preserve cultural heritage. Inevitably, the lack of ICT policy on a national level impacts funding, vocational training, leadership and autonomy to act independently, disengaging participants from the preservation process.

\section{Lack of ICT policy}

A significant number of participants commented on the lack of an ICT policy on the national level and therefore the missing direction on how ICT should be leveraged, also with regards to preserving the cultural roots. Three participants acknowledged 
the existence of a national ICT policy, however, were unable to advise where it can be accessed or how it can be attained. Lupe explains:

"We have a national ICT policy which I'm sure is languishing somewhere. I have a copy but I don't have a copy I can give you. Umm.. but umm.. that is supposed to provide the regulation for the service for that particular sector but I don't think it has been activated. So it's still languishing somewhere and ministries are still carrying on doing their own thing".

Mele remarked that she had been advised by another Tongan member of the existence of an IT policy, however, herself was unaware of one.

Apart from these three participants, the remaining participants were not even aware of an ICT policy. Leka highlights, "That's one of the things they've brought up recently cause I don't think Tonga has any IT policies". Fusi also comments, "In everything there should be legislation, because then it is easier to do our job for example, like at the moment there is no policy only the Land Act that we hold on to". Fusi continues on the lack of policy and sharing or information on historical sites:

"We have the capacity, we can develop our own web service, but we don't have a policy...We have started to develop a policy, but it is not yet completed. But this policy is only for data sharing, it's almost completed. However, we don't know an act that the policy can fall under and that can validate it".

The absence of an administrative and legal framework to ensure the safeguarding of Tonga's heritage, is a point of exasperation for participants. According to the participants, an ICT policy is needed to preserve Tonga's heritage, provide protection from exploitation and empower local Tongan's partaking in the preservation process within their workplace.

\section{Lack of Leadership and Direction}

The missing ICT policy on governmental level affects the leadership and decision making in public agencies like the Ministries. Due to the lack of clear processes and instructions from leaders in the institutions of how to leverage ICT to preserve cultural heritage, employees are often uncertain if and how ICT can be used in their daily work to safeguard cultural heritage, even if the necessary technology is available and cultural heritage is identified.

\section{Governmental Level}

Tonga is currently going through a process of political change with the democratic party being in power. The government is focusing on other topics like their new democratic model, and not prioritising the preservation of cultural heritage as outlined by 'Uasimoa:

"With what Tonga is going through now with the change of politics and democracy, the priorities of um things for them is quite different and trying to push this whole piece and this idea into a government proposal is I think it would be probably a third or fourth issue to handle to draw their attention to. You can probably know by now that Tonga is just too focused on just the change in the democracy".

'Uasimoa, highlights that the leadership changes on government level affects strategic direction and therefore, results in continual policy variations. ICT direction 
depends on the party in power, and currently the development of an ICT strategy that can provide legislation and policies to guide preservation work is not a high priority. This is in part due to Tonga's reliance on foreign aid, therefore, priorities are often centered on the agenda and priorities of the foreign nations. For example, the joint commitment for development agreement 2016-2018 between New Zealand and Tonga prioritised: energy, law and justice and education [18].

The lack of leadership and ICT direction means an absent frame work for organisations to prioritise and advance the preservation of cultural heritage. Therefore, ICT is utilised very minimally in the preservation process, as priorities of leaders are directed elsewhere.

\section{Institutional Level}

The lack of direction and guidelines on the preservation of cultural heritage in general and the use of IT to safeguard it is reflected in the management and operation of public agencies. Fusi explains that there is a disconnect between the department she works in, which collects and stores information on historical sites, and the office that administers and approves land ownership. Fusi uses satellite data to identify and register historical sites. However, if a potential land owner visits the front office, the front office personnel does not request further information from her department to check if a historical site is part of the requested land. There are neither instructions in place that the front office must request the necessary information from the back office nor are the two IT systems integrated so that the front office could easily access the information through a shared database. Fusi claims that this problem is mainly caused by not having a leader with technical skills who would understand the potential of technology and to integrate the two systems.

"Yes, what we are waiting for is someone on the level of Director so that our work can be managed properly, we need someone on that level who understands technology." (Fusi). Furthermore, Leka explains, "we have the capacity (referring to skills) to get the job done but like I said what we need is someone at the top" (referring to a leader for the department).

The participants highlighted that the team leaders don't have a clear strategy and vision on how ICT can be utilised within the workplace. This is particularly frustrating for the participants as they value their own cultural heritage and would have the necessary technological skills to engage in the preservation process. However, they are disengaged due to a lack of direction and guidance from their leaders.

Lack of resources, the missing policies and leadership result in lack of funding, equipment and training of the participants. Without the required financial and technical support participants won't receive any training on how ICT can be used to preserve cultural heritage. Therefore, the capacity in which ICT can be utilised in the preservation process in Tonga is not realised. Despite their limitations, 'Uasimoa explains that they "are trying to speak up and seek help from people for us here staff to be trained on how to handle the files and how to take them and convert them to technology, digital". Although there has been an effort to commence the digitisation of its historical records within' Uasimoa's workplace, she remarks that "we are very far behind". 


\subsection{Bottom-up Initiatives to Preserve Cultural Heritage}

In spite of the challenges experienced by participants, we found that small ICT initiatives are being implemented by individuals to preserve cultural heritage. Such initiatives are not bound to a hierarchy or a position, therefore, individuals can be proactive and take initiative without violating the hierarchical norms which are highly important in the Tongan culture. Tongans would not act against the instructions of their superior as they respect their authority.

In Tonga, there are grass root initiatives such as The Nuku'alofa Film Festival initiated in 2015, to recount Tongan and Samoan myths encouraging story telling through film making. Although the festival has evolved to include films on current issues for example climate change, it has provided a good platform for encouraging the use of video technology to preserve the cultural roots of the two countries [16]. Lisiua drawing on her personal experience of partaking in grass-root initiatives to preserve heritage comments:

"It has been difficult to sell the idea to locals for a variety of reasons. A lot have agreed that it is an important initiative to document our history and stories via films. One major hurdle will always be that there is no local funding that would allow these visions to happen. But nevertheless, we at the (pseudonym initiative) believe that it will take time. There are a few of us, working little odd jobs in films to make ends meet and at the same time plan to pursue this important vision".

Other interactive bottom-up initiatives can be observed on social media platforms

such as Facebook. For example, the Facebook page 'Fale a Matapule', with

14,495 members, disseminates traditional knowledge and ensures its accuracy through online discussions. Furthermore, the video sharing platform YouTube was recognized by the participants as a suitable tool to publish and broadcast their knowledge, their experiences and their handcrafts to a wide audience.

"There are so many ways I think we can use to preserve our culture digitally. Not only through films but also protecting them online. In the forms of website, on YouTube etc. I was lucky to have been funded by ICHCP (Intangible Cultural Heritage for Asia Pacific) in 2016 to make a short documentary on the making of our fine mats KIE. This short video is available on YouTube and I think it is important for students to learn about the knowledge developed by our people on how to make these beautiful fine mats. In 2016 I made a very short film with Coconet on "How to tau'olunga”, which shows some very basic tau'olunga movements. Again, it is available on YouTube".

Also, families are actively engaging in the preservation process as identified by Sione. Often, their goal is to safeguard their own family roots so that , family members record oral stories of their family genealogies and traditional songs, dances and stories using video cameras. Kepu explains during an informal talanoa that his daughter audio records conversations regarding genealogy and historical accounts passed down from previous generations. It seems that the local Tongans are engaging in the process of preserving cultural heritage using ICT. This highlights that Tongans are conscious of the need for preserving cultural heritage and are utilising ICT tools to do so. 


\subsection{Conclusion}

The goal of this research project was to explore how ICT is utilised in the process of preserving cultural heritage in Tonga. Taking a social embeddedness approach and investigating the phenomenon in its local context we found that besides traditional methods such as orally from one generation to the next, storytelling in faiva, the talanoa around kava circles, and participating in traditional artwork such as ngatu making (tapa making).

ICT is considered a valuable option to preserve cultural heritage in Tonga. However, due to the lack of an ICT strategy on governmental level, institutions are unable to leverage ICT to its fullest potential to protect historical documents, traditional arts, traditional knowledge and significant historical sites in Tonga. Due to the absence of an ICT policy and therefore lacking legitimization there is no funding, vocational training, and autonomy to act. This missing support leads to frustration of the participants and affects innovation

within organisations. However, out of this restrictive and confined environment positive IS innovation has emerged in the form of bottom-up initiatives. These grass root initiatives are occurring on an individual level stirred by hopes, concern and expectations to preserve one's heritage. Although, the goal of this study was to explore how Tongans use ICT to preserve cultural heritage, it is important to emphasize that the traditional methods have carried Tonga's rich culture for many centuries and are still the most common means to safeguard the cultural roots.

In line with the social embeddedness approach it is against this background that we developed the following recommendations that cater Tongan's appreciations for traditional means as well as the potential of ICT:

Firstly, the preservation of cultural heritage in Tonga is essential to the continuance of the culture in the face of globalisation, technological advancements and modernisation. Currently some archaeological sites such as the sia heu lupe, are at great risk of complete demolition and with the destruction of physical historical artefacts, cultural heritage is at risk of erosion. Therefore, we recommend the implementation of clear guidelines on a governmental level on how to preserve cultural heritage and to develop an ICT strategy to leverage the potential of technology to safeguard cultural heritage in Tonga. Secondly, processes and clear instructions especially within government agents and royal agents have to be developed in order to guide employees in how to preserve cultural heritage. These processes and instructions should factor in traditional methods of preservation and the potential of ICT to provide a much more meaningful experience for local Tongans who value the benefit of both. Lastly, there needs to be better financial support and recognition for bottom-up initiatives utilising ICT. 


\section{Reference}

[1] D. V. Burley, "Sport, Status, and Field Monuments in the Polynesian Chiefdom of Tonga: The Pigeon Snaring Mounds of Northern Ha’apai,” J. Field Archaeol., vol. 23, no. 4, pp. 421-435, 1996.

[2] “The Fiji Museum - Virtual Museum.” [Online]. Available: http://virtual.fijimuseum.org.fj/index.php?view=objects\&id=61. [Accessed: 30-Jan-2019].

[3] D. R. Hancock and B. Algozzine, "Stages of doing case study research," in Doing case study research: A practical guide for beginning researchers, 3rd ed., vol. 1, New York: Teachers College Press, pp. 15-73.

[4] T. M. Vaioleti, "Talanoa Research Methodology: A Developing Position on Pacific Research,” Waikato J. Educ., vol. 12, pp. 21-34, Jan. 2006.

[5] E. J. Techera, "Safeguarding cultural heritage: Law and policy in Fiji," J. Cult. Herit., vol. 12, no. 3, pp. 329-334, Jul. 2011.

[6] C. Avgerou, "Information Systems in Developing Countries: A Critical Research Review,” J. Inf. Technol., vol. 23, no. 3, pp. 133-146, Sep. 2008.

[7] Z. Abd Manaf and A. Ismail, "Malaysian cultural heritage at risk?: A case study of digitisation projects,” Libr. Rev., vol. 59, no. 2, pp. 107-116, Mar. 2010.

[8] A. Belhi, A. Bouras, and S. Foufou, "Digitization and preservation of cultural heritage: The CEPROQHA approach,” in 2017 11th International Conference on Software, Knowledge, Information Management and Applications (SKIMA), 2017, pp. 1-7.

[9] D. E. Leidner and T. Kayworth, "Review: A Review of Culture in Information Systems Research: Toward a Theory of Information Technology Culture Conflict,” MIS Q., vol. 30, no. 2, pp. 357-399, 2006.

[10] R. Heeks, “Understanding ICT4D,” in Information and Communication Technology for Development (ICT4D), Milton, UNITED KINGDOM: Routledge, 2017.

[11] C. L. Mann, "Information Technologies and International Development: Conceptual Clarity in the Search for Commonality and Diversity,” Inf. Technol. Int. Dev., vol. 1, no. 2, pp. 67-79-79, Dec. 2003.

[12] G. Walsham, "ICT4D research: reflections on history and future agenda,” Inf. Technol. Dev., vol. 23, no. 1, pp. 18-41, 2017.

[13] “05-1. Kupesi A Creative Tradition of Tonga.pdf.” .

[14] V. Braun and V. Clarke, "Using thematic analysis in psychology," Qual. Res. Psychol., vol. 3, no. 2, pp. 77-101, Jan. 2006.

[15] J. Olutimayin, “Adopting Modern Information Technology in the South Pacific: A Process of Development, Preservation or Underdevelopment of the Culture?” Electron. J. Inf. Syst. Dev. Ctries., vol. 9, no. 1, pp. 1-12, 2002.

[16] M. Kēpa and L. Manu'atu, "Pedagogical Decolonization: Impacts of the European/ Pākehā Society on the Education of Tongan People in Aotearoa, New Zealand,” Am. Behav. Sci., vol. 51, no. 12, pp. 1801-1816, Aug. 2008.

[17] H. 'Okusitino Māhina, "From Vale (Ignorance) to 'ILO (Knowledge) to Poto (Skill) the Tongan Theory of Ako (Education): Theorising Old Problems Anew,” Altern. Int. J. Indig. Peoples, vol. 4, no. 1, pp. 67-96, Jun. 2008. 
[18] N. Z. M. of F. A. and Trade, “Development partnership with Tonga,” New Zealand Ministry of Foreign Affairs and Trade. [Online]. Available: https://www.mfat.govt.nz/en/ aid-and-development/our-work-in-the-pacific/tonga/. [Accessed: 02-Feb-2019]. 